\title{
CONTRIBUTION OF GEOLOGICAL MAPPING IN ROAD CONSTRUCTION: AN EXAMPLE FROM VERIA - KOZANI NATIONAL ROAD, KASTANIA AREA
}

\author{
Georgiadis G. A. ${ }^{1}$, Tranos M. D. ${ }^{1}$, Makedon Th. K. ${ }^{1}$, and Dimopoulos G. Ch. ${ }^{1}$ \\ ${ }^{1}$ Aristotle University of Thessaloniki, School of Geology, Department of Geology, 54124 \\ Thessaloniki,Greece,gggk@geo.auth.gr,tranos@geo,auth.gr,thomas@geo.auth.gr, \\ gdimop@geo.auth.gr
}

\begin{abstract}
Road construction is a complex and multipart work that is decisively depended on the geological investigation of the area of interest. The geological investigation, which ought to be carried out from the early stages of the study and construction, contributes significantly in the cost reduction and corresponding increase of the construction safety. The proposed methodology that should be implemented during the geological investigation for this kind of constructions includes geological mapping and construction of geological and engineering geological maps. These maps display, in each case, the necessary data and are supplemented by geological crosssections as well as stereographic projections (e.g. Schmidt diagrams), which evaluate the tectonic conditions of the area and the stability conditions of artificial road slopes. An example of geological investigation based on the above methodology is presented, regarding the Kastania section of the Veria-Kozani (old) national road. Key words: Engineering geology, slope stability, rock mass, discontinuities.
\end{abstract}

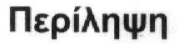

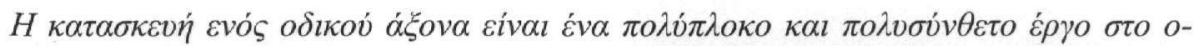

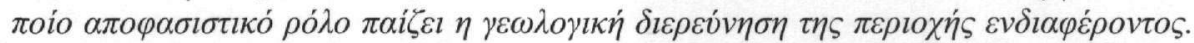

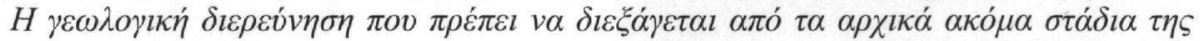

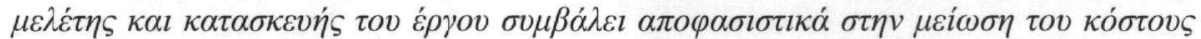

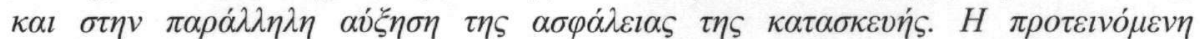

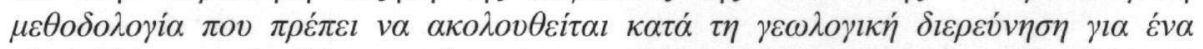

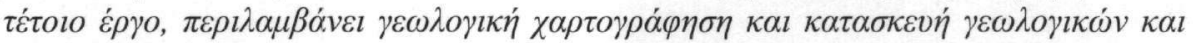

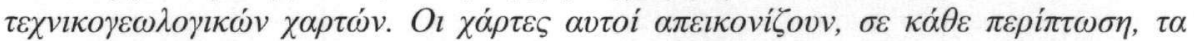

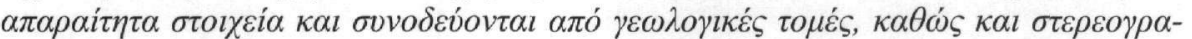

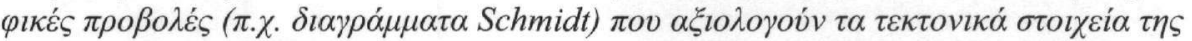

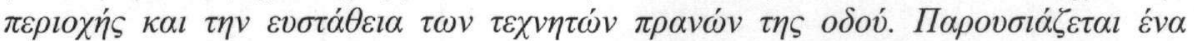

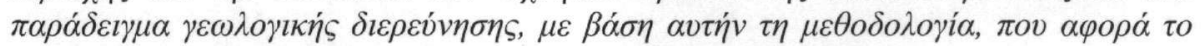

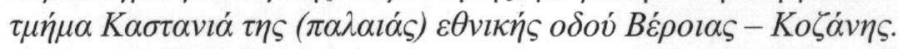

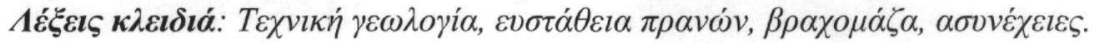




\section{Introduction}

A decisive part in the alignment, study and construction of road works is contributed by the geological investigation of the foundation bedrock of the construction, which is basically carried out by geological mapping of the area of interest. From the evaluation of the geological mapping data the optimal road alignment is selected, thus avoiding the hazardous areas with respect to the stability of the created cut slopes and the safety of constructions (i.e. tunnels etc.) but also to the handling of other problems like location of borrow materials and stockpiling areas.

The decision upon the road construction according to the data and outcome of the geological mapping, results in a significant reduction of the construction cost with a corresponding increase of the construction safety. The paper proposes a composite presentation of the main elements of geological mapping regarding the artificial slope stability. An example of such an investigation is presented from the Kastania section of the (old) national road of Veria - Kozani. The selection of this example was based on the fact that the above road section crosses the Vermion mountain range, forming artificial slopes of variable orientations and in various geological formations which possess different mechanical characteristics thus providing the possibility to evaluate different conditions of potential instabilities.

\section{Proposed methodology}

The geological mapping carried out along the alignment of a road work aims, as already mentioned, to contribute in the safest construction possible at the lowest cost possible. In order to accomplish this, the geological mapping should implement a specific methodology. The proposed methodology follows the next stages:

- Presentation and assessment of the geology of the broader area. This is depicted, by means of symbolisms or symbols, in a surface representation of:

- The rock formations and geological strata with their geometric features (strike and dip).

- The major tectonic fault structures.

From the evaluation of the geology of the broader area we seek:

- The stratigraphy of the area (the age sequence of the formations).

- The faults (normal, inverse and strike slip) that intersect the area with their orientation and length.

- Presentation and assessment of the geology of the road alignment area. This is carried out at a large scale and covers a distance across the alignment area from 1 to $2 \mathrm{~km}$ wide. This mapping aims to determine the layout of rock formations in the area of construction, the rock mass and soil mass structures, as well as their mechanical characteristics that will affect the safety of the construction.

- The geological works are presented by surface representation (mapping), while geological cross-sections present the structure of the area in depth. The suitability of the initial alignment and the need of repositioning of the road axis in another location inside the zone of the original course, are both affected and should therefore be investigated and evaluated by the geologist, by:

- The area relief.

- The orientation (strike and dip) of the rock formations in respect to the orientation of the road axis.

- The tectonic conditions and fracturing of the rock mass.

- The condition of discontinuities (fractures) and rock mass quality. 
- The excavation, hauling and stockpiling of the excavation materials (locations of borrow pits, stockpiling areas).

- Construction of cross-sections along the road axis to investigate the relation of the morphology to the road level ("red line"). The red line is positioned on these sections in order to be evaluated with respect to the final shape of the artificial cut slope and the volume of excavations.

- By the graphic representation of surface rocks and formations in the zone of interest with their geometric features, an impression of the formations' stratigraphy is given along with their position and the area they occupy along the orientated road axis. Their relative position with the apparent surface area, the inclination and thickness along the above orientation are presented with the geological cross-sections, which are constructed in the same scale as the map and are presented along with it. The above graphic representations provide the possibility of quantitative assessment of the excavations that will be required for each formation encountered along the road's red line.

- The tectonic picture and rock mass fracturing are given in the surface geological mapping by the direct display of the major fault structures as well as by tectonic diagrams (i.e. Schmidt projections). All the discontinuities encountered along the road alignment are recorded in different homogeneous zones with their orientation, density (degree of fracturing) and length. Subsequently they are elaborated in Schmidt projections where the number of joint sets and their average orientations are calculated. The Schmidt diagrams that illustrate the tectonic conditions of the rock mass in different locations of the road axis are supplementary to the geological map of the alignment zone. The orientation and number of discontinuities determine the shape and magnitude of detached blocks (planar and wedge-shaped) in the future cut slope with the specified orientation. Schmidt diagrams are used in order to investigate the risk on the slope and contribute in the potential reorientation of the road axis and location of the construction, as well as in the conclusive decision upon the inclination of the cut slope.

- The geological mapping includes also the observations on the condition of discontinuities, their mechanical behavior and the rock mass quality. The discontinuities are described as to their degree of weathering, aperture (opening), infilling material, surface roughness, development and density. These procedures approximately determine the mechanical parameters of the weak areas of the rock mass and the size of rock wedges and fractured loose blocks. An initial analysis is carried out on the sliding mechanisms of the cut slope and an estimate of the level of hazard for the slope is made based on the initial orientation of the road axis. By possible repositioning of the unsafe orientation to nearby locations with more favorable orientations, potential sliding can be avoided with immediate and considerable reduction of the construction cost. The above analysis is performed by the construction of diagrams of sliding failure mechanisms on Schmidt projections supplementary to the geological map.

An implementation of all the above is the geological mapping carried out along the (old) road of Veria - Kozani in the Kastania area. The mapped area is located in the Prefecture of Imathia, 15 $\mathrm{km} \mathrm{SSW}$ of the city of Veria.

\section{Geological framework}

The study area is made up of pre-alpine and alpine rocks of the Pelagonian zone (Kilias and Mountrakis 1989). This zone consists from the bottom to top of: (a) gneisses, schists, amphibolites and meta-granites of Paleozoic age that make up the crystalline basement, (b) the Permo-Triassic slightly metamorphosed clastic sediments, (c) the Triassic - Jurassic carbonate rocks, (d) the 
ophiolites with accompanying deep sea sediments of Jurassic age and finally (e) the Middle - Late Cretaceous transgressional carbonate rocks with the Late Maastrichtian - Lower Paleocene flysch.

The final orogenic stage of Eocene - Oligocene (Kilias and Mountrakis 1989) is associated with the final thrusting of the Almopia zone formations over the Pelagonian zone and the final imbrications of the Pelagonian rocks. Since the Late Miocene, the area is dominated by an extensional regime with NE-SW trend of extension during Late Miocene - Pliocene and N-S trend from Early Pleistocene up to now (Mercier et al.1989). The area is generally close to the Aliakmon river fault zone (Mountrakis et al. 2006).

\section{Geology of the Kastania region}

Geological mapping in the study area has been carried out (Ouzounis et al. 2002, Photiadis 2004) but with a different scope and objectives than the present paper, whereas the geological map sheet of "Velvendos" has not been published yet by the I.G.M.E. In the frame of this paper the geological mapping of the area was carried out for a length of approximately $9 \mathrm{~km}$ and a 1:20000 scale.

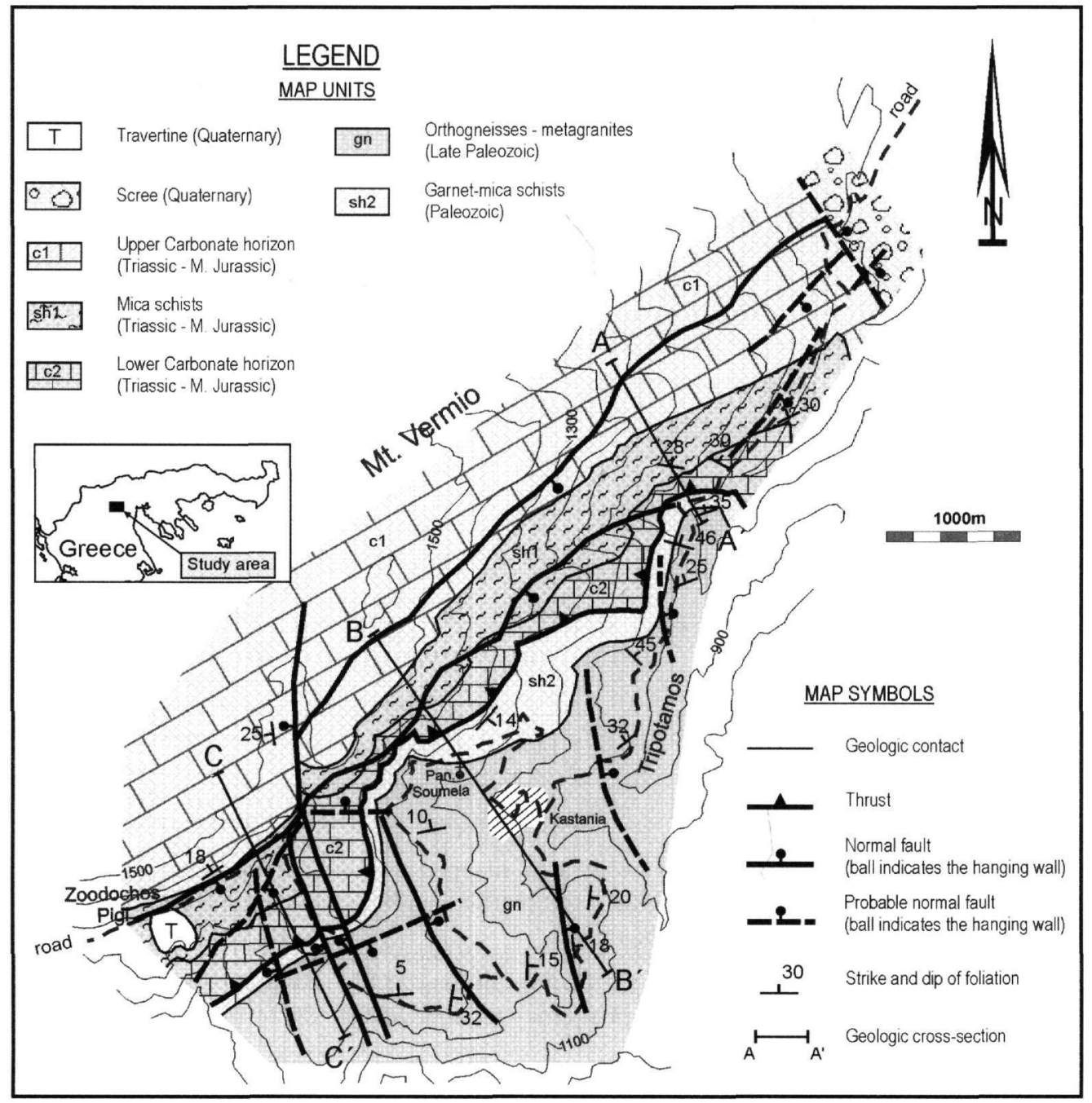

Figure 1 - Geological map of the area 
From the mapping the resulting geological structure of the area is as follows (Fig. 1):

Orthogneisses - metagranites. These are gneisseous granites of brownish-grey, grey and light grey colour of Carboniferous age (Yarwood and Aftalion 1976, Mountrakis 1983, Koroneos et al. 2000 ) that locally maintain their original granitic texture.

Garnet - mica schists. Quartzo-feldsphatic,garnet, two-mica schists, of brown, greenish-grey colour and Palaeozoic age. In some locations small amphibolitic bodies of dark green colour and a few meters thick were observed parallel to the foliation, and also quartz veins of small length and few centimetres thick.

Lower carbonate horizon. Massive coarse-grained recrystallized limestones-marbles of characteristic white colour, possibly part of the Triassic - Jurassic carbonate cover of the Pelagonian zone (Mountrakis 1983). Their contact with the previous underlying formation is through a mylonitic zone of variable thickness (less than one meter).

Mica schists. Quartzo-feldsphatic, chloritic, mica schists of greenish-grey, light grey and grey colour. Within the schists, aplite and quartz veins are orientated parallel to the foliation. A Triassic-Jurassic age is assigned to this formation.

Upper carbonate horizon. Consists of white to whitish-grey recrystallized limestones and marbles containing mica flakes. The erosion surfaces present a characteristic beige colour while to the northeast of the study area, this horizon shows intense karstification and is the main Triassic Jurassic carbonate cover of the Pelagonian zone.

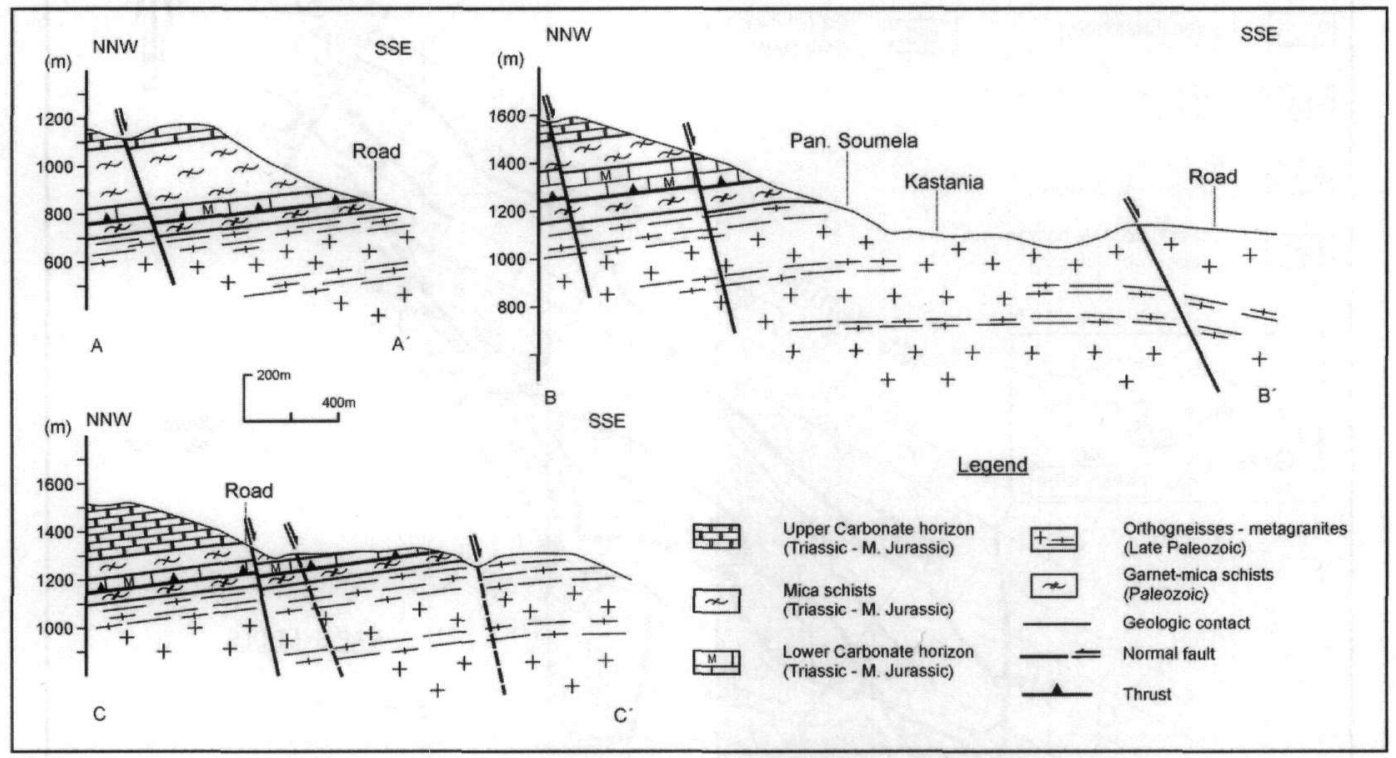

Figure 2 - Geological cross-sections showing the structure of the area

More recent Quaternary soil deposits were also mapped which include scree of red colour containing boulders and fragments of schists and marbles within silty-sandy material as well as a travertine outcrop in the area of Zoodochos Pigi.

All the above formations are depicted in the geological map of Fig. 1 while part of the geological structure of the area is shown in the geological cross-sections of Fig. 2.

The rocks of the study area are generally dipping north with very small to small dip angles. The foliation presents a variable dip direction from NW to NE with the orthogneisses - metagranites at the south-eastern edge of the mapped area dipping gently to the east. This differentiation in the dip directions combined with the two concentrations of the foliation distribution in the density contour 
diagram (Fig. 3a) possibly indicate the presence of a very open anticline structure (up swelling) of N-S to NNE-SSW axial trend.

The mapped faults are mainly striking NE-SW and NNW-SSE. The former are normal faults dipping to the SE at relatively large angles. These faults are developed parallel to the active fault zone of Aliakmon River (Mountrakis et al. 2006). Particularly significant is the fault traversing Zoodochos Pigi with a length of about $6 \mathrm{~km}$, whose activity is associated with the deposition of travertine during the Quaternary (Fig. 1). The NNW-SSE striking faults are normal faults of smaller length than the previous ones dipping both to the NE and SW at large angles.

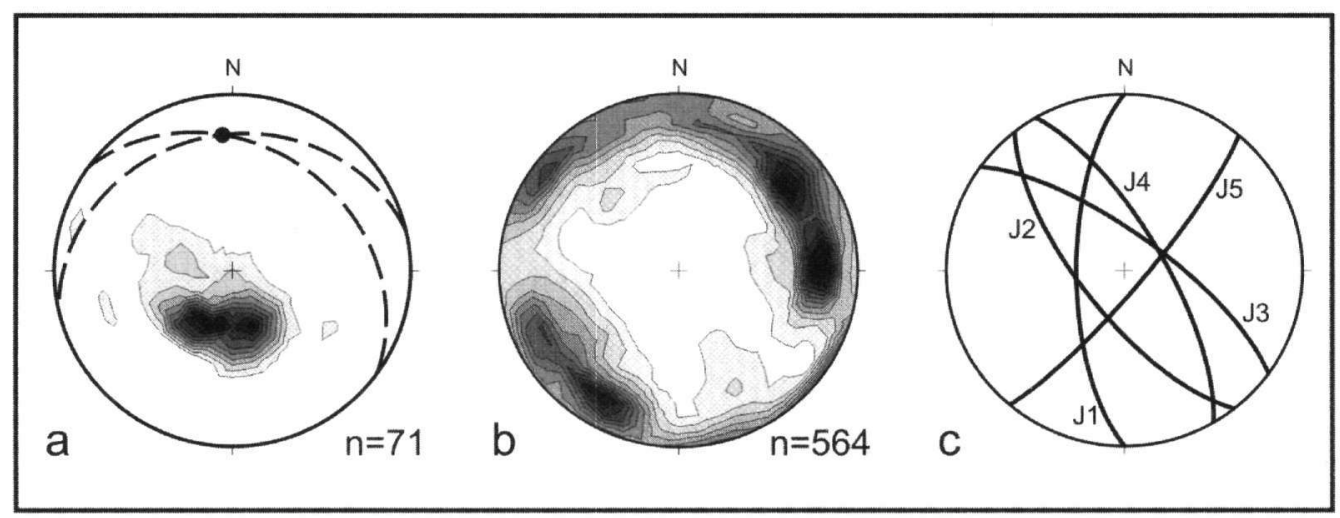

Figure 3 - Stereo-projections (equal area, lower hemisphere): (a) contour diagram of foliation poles, (b) contour diagram of joint poles in the study area, (c) the five major joint sets

\section{Geological mapping of the road axis zone}

The geological mapping along the national road axis was carried out at a scale of 1:5000. The proposed methodology was applied giving emphasis to the display of surface formations, the recording of discontinuities, fracture zones and generally weak zones that might generate problems of instability and operation of the existing national road.

Two sections of the national road were selected. The selection was based on the facts that in both sections the road traverses the entirety of rocks encountered in the study area and that the created cut slopes bear different orientations. Thus it was possible to investigate the stability of slopes of different orientations and in rocks of different mechanical behaviour. The data recorded during this geological mapping concerned the type of geological formations, the degree of weathering and the location of areas of intense fracturing and loosening of the rock mass due to the presence of zones with poor mechanical characteristics. Special emphasis was given in the recording and description of discontinuities (foliation, joints, faults etc.) along the road in order to be evaluated in the analysis of the road's slope stability. These procedures include the placement of discontinuities on the map, wherever and whenever this was possible (i.e. permitted by the map scale), with simultaneous collection of data referring to their orientation, length, density and aperture. Two geological maps are given (maps A and B, Figs 4 and 5 respectively) which present road sections with geological formations of similar mechanical characteristics. Schmidt diagrams showing the recorded discontinuities in each road section accompany these maps.

In map A (Fig. 4) the national road is generally trending NE-SW while in map B (Fig. 5) the national road follows a zigzag development. In both maps the road is crossing sequentially all the alpine and pre-alpine formations encountered in the broader area, while a small segment in map A is covered by Quaternary scree. The geological formations are: 
The orthogneisses - metagranites which in map A appear as granitic gneisses and augen gneisses while in map B mostly as granitic gneisses with evident schistocity, whereas at places the primary granitic texture of the rocks is distinguished. The rock mass is characterized as sound (fresh) to moderately weathered and in certain locations only (map B) highly to completely weathered rated as class IV-V (ISRM 1981), with soil-like mechanical characteristics. Map B shows a zone of intense rock fracturing in which rock detachments and rock falls are noted.

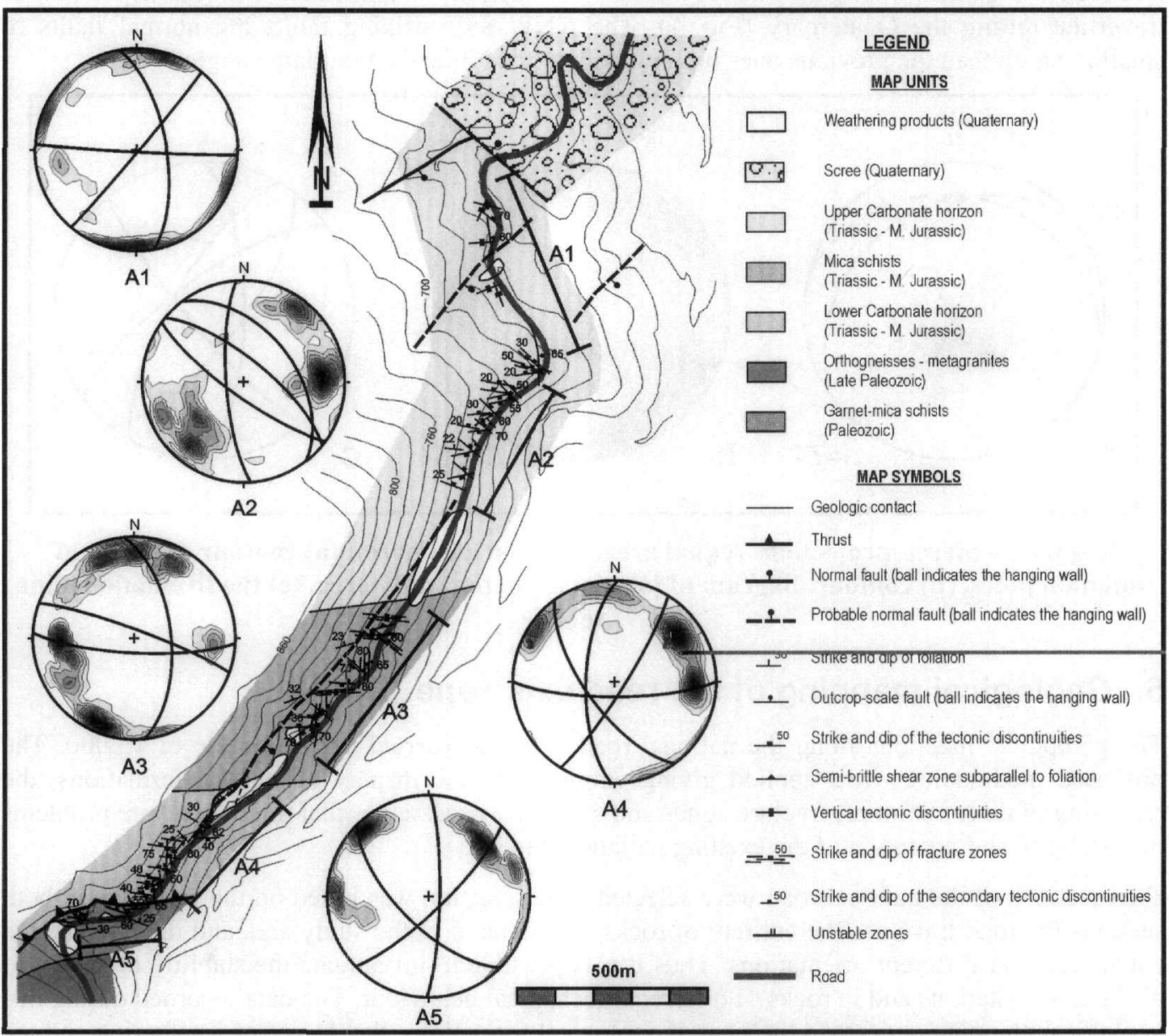

Figure 4 - Engineering geological map A

In the area of map A the garnet-mica schists present an intercalation of dark green orthoamphibolite, a few meters thick, parallel to the foliation. This formation, which in the maps involves only a small portion of the road slopes, appears sound to slightly weathered with foliation dipping NNW-NNE at small angles.

The lower carbonate horizon with massive, white, coarse-grained marbles is sound to slightly weathered. This formation is dipping to the NNE at small dip angles and overlays tectonically the garnet-mica schists. The higher cut slopes in the area of map A are located within this formation. They were created during the excavation of a quarry for aggregate extraction and do not seem to present instability problems despite their height.

The mica schists present a foliation dipping NNW at small angles. Within the schists, quartz veins and aplitic bodies show up parallel to the schistocity. The formation is sound to slightly weathered. 
In some locations it appears intensely schistose, presenting local zones of limited size with high density of discontinuities.

The upper carbonate horizon surfaces noticeably, presenting foliation of small dip angles and NNE (map A) to NNW (map B) dip directions, whereas to the northern part of the national road (map B), the foliation is almost horizontal. In map A the limit with the underlying formation is not evident because of a small size cover of talus probably due to a fault of NNE-SSW strike. It should be noted that in map B, due to the faulting of the area, small segments of the formation appear as residual blocks both within the mica schist and the lower carbonate horizon.

The scree originates from the weathering of the bedrock formations. It appears incoherent, red colored, with boulders and angular fragments of schists and mainly marbles, inside clayey-sandy matrix. This formation is only shown in map A and the slopes created in that area are of small height.

Finally exposed and mapped in the area are small sized loose formations of weathered materials of Holocene age and few meters thick. These are products of weathering of the surrounding rocks, encountered at the base of steep slopes and inside streams.

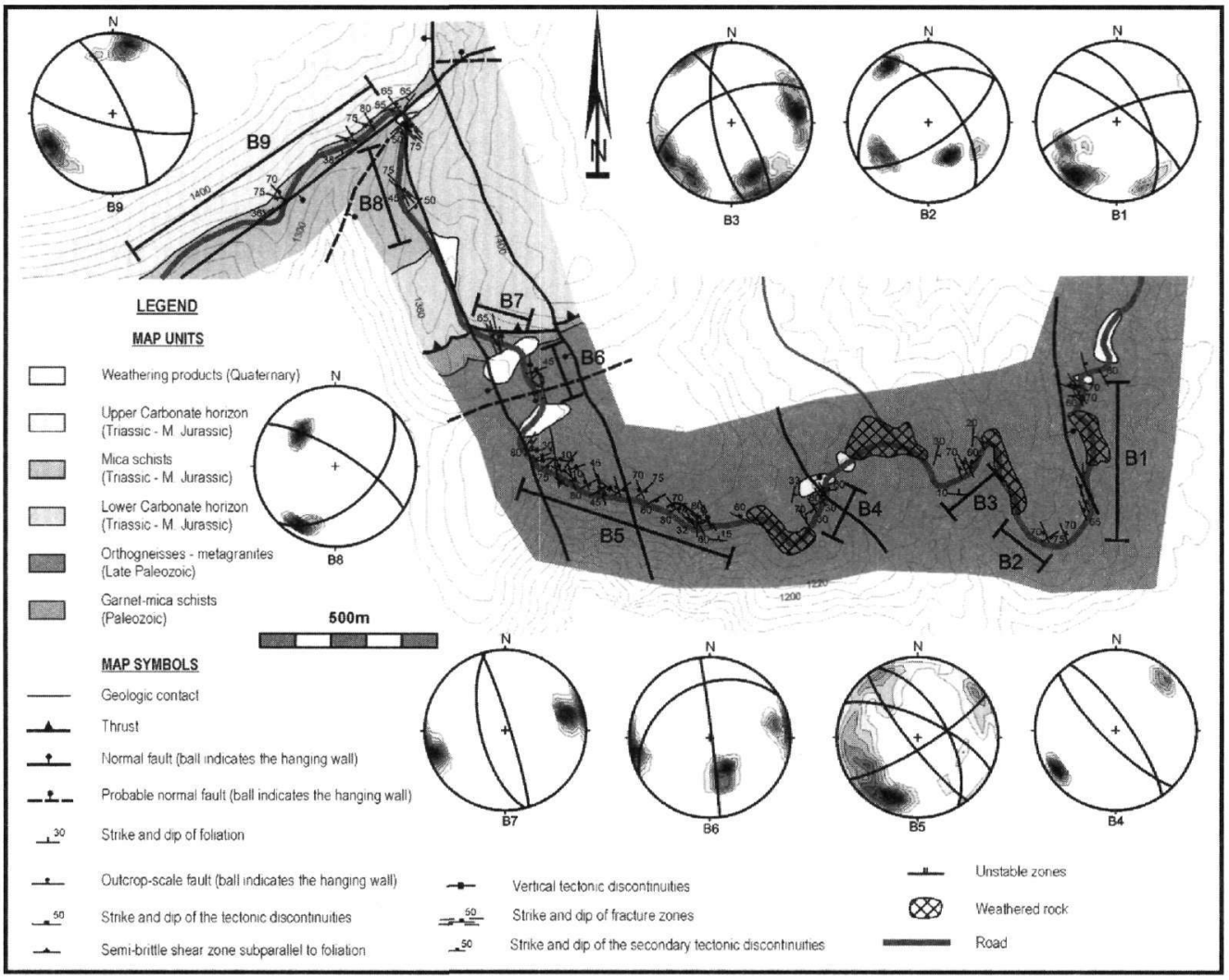

Figure 5 - Engineering geological map B

\section{Rock mass fracture characteristics}

As already mentioned the mapping gives emphasis in the recording of the location and the characteristics of tectonic discontinuities and especially joints. The maps are supplemented with diagrams regarding joints located and recorded in sections of the road and used in the stability analysis of the slopes in these locations. It can be mentioned that from the projection of the joints 
on Schmidt diagram five major joint sets turn out (Figs $3 b, c)$, with different characteristics depending on the lithological type they are encountered in.

\section{$\mathrm{J}_{1}$ - joint set $\left(270^{\circ} / 68^{\circ}\right)$}

The joints in this set present very small $(<1 \mathrm{~m})$ to medium $(3-10 \mathrm{~m})$ persistence (after Barton 1978 ) and narrow $(6-20 \mathrm{~mm})$ to very wide $(0,6-2 \mathrm{~m})$ spacing (degree of fracturing $1<\mathrm{k}_{1}<10 \mathrm{~m}^{-1}$ ). Their aperture is small to very small (2-6mm) (after Anon 1977). The dip directions of the set vary from $250^{\circ}$ to $284^{\circ}$ and the dip angles between $48^{\circ}$ and $83^{\circ}$.

\section{$\mathrm{J}_{2}$ - joint set $\left(232^{\circ} / 70^{\circ}\right)$}

The dip directions of this set vary between $212^{\circ}$ and $250^{\circ}$ and the dip angles between $55^{\circ}$ and $85^{\circ}$. They present variable persistence from very small $(<1 \mathrm{~m})$ to medium $(3-10 \mathrm{~m})$ and narrow spacing $(6-20 \mathrm{~mm})$ for those with small length, to very wide $(0,6-2 \mathrm{~m})$ for those with more length (degree of fracturing $\left.1<\mathrm{k}_{2}<10 \mathrm{~m}^{-1}\right)$. They are of extremely small aperture $(<2 \mathrm{~mm})$ or completely closed.

\section{$\mathbf{J}_{3}$ - joint set $\left(036^{\circ} / 73^{\circ}\right)$}

The dip directions of this set vary between $15^{\circ}$ and $55^{\circ}$ and their dip angles between $53^{\circ}$ and $90^{\circ}$. Their persistence varies between very small $(<1 \mathrm{~m})$ and small $(1-3 \mathrm{~m})$ with narrow $(6-20 \mathrm{~mm})$ to very wide $(0,6-2 \mathrm{~m})$ spacing (degree of fracturing $1<\mathrm{k}_{3}<10 \mathrm{~m}^{-1}$ ). Their aperture is very small (2-6 mm) to none (closed).

\section{$\mathrm{J}_{4}-$ joint set $\left(060^{\circ} / 72^{\circ}\right)$}

The dip directions of this set vary between $53^{\circ}$ and $90^{\circ}$ and their dip angles between $50^{\circ}$ and $90^{\circ}$. Their persistence varies between very small $(<1 \mathrm{~m})$ and small $(1-3 \mathrm{~m})$ and their spacing from medium (20-60 mm) for those with small length $\left(k_{4,1}=20 \mathrm{~m}^{-1}\right)$, to extremely wide $(>2 \mathrm{~m})$ for those with more length $\left(\mathrm{k}_{4,2} \leq 30 \mathrm{~m}^{-1}\right)$. Their aperture is very small $(2-6 \mathrm{~mm})$ to none (closed).

\section{$\mathrm{J}_{5}-$ joint set $\left(130^{\circ} / 81^{\circ}\right)$}

The dip directions of this set vary between $105^{\circ}$ and $150^{\circ}$ and the joints dip very steeply $\left(>70^{\circ}\right)$. Their persistence varies between very small $(<1 \mathrm{~m})$ to large $(10-20 \mathrm{~m})$, with narrow $(6-20 \mathrm{~mm})$ to very wide $(0,6-2 \mathrm{~m})$ spacing $\left(0,5<\mathrm{k}_{5}<10 \mathrm{~m}^{-1}\right)$. Their aperture is very small to small $(6-20 \mathrm{~mm})$. This set appears to be associated with the NE-SW striking faults that appear in the study area.

Apart from the above five discontinuity sets, discontinuities parallel to the foliations of the formations were also recorded. Their characteristics depend on the type of rock that they appear in. Their general orientation is parallel to the rocks' foliation and they show very small to medium persistence. They have medium to very wide spacing $\left(0,7 \leq k<10 \mathrm{~m}^{-1}\right)$.

\section{Layout and stability of the road slopes}

The sum of slopes in the studied sections of the Veria - Kozani national road, is classified as rock slopes. Only small segments of the road include slopes in soil formations but these are limited in area and height. For the needs of the stability analysis, the road sections mapped at a 1:5000 scale were divided into segments depending on the slope orientation and the geological formation encountered by the road. Such an analysis at an early stage of road design is usually based on a deterministic approach of the parameters affecting the slope stability. This approach by no means overlooks the influence of the variation of discontinuity and strength parameters. However it is not practically applicable at this stage, in which the main issue is the type or mechanism of expected failures as well as a first estimate of the factor of safety of the slopes. There is extensive literature on other approaches of stability analysis in road design, which include probabilistic analysis (Park et al. 2005) or specific methodologies based on particular slope cases (Christaras et al. 1997). The stability analysis in our case included the evaluation of the discontinuities recorded in the respective segments of the road (Fig. 6), which are presented in the maps of Figs 4 and 5 with 
Schmidt projection diagrams. Markland's test and Hocking's improvement (Hoek and Bray 1981) were applied to determine first of all the type of potential failure (planar failure, wedge failure) and, subsequently, the sliding mechanism for the calculation of the factor of safety of the slope.

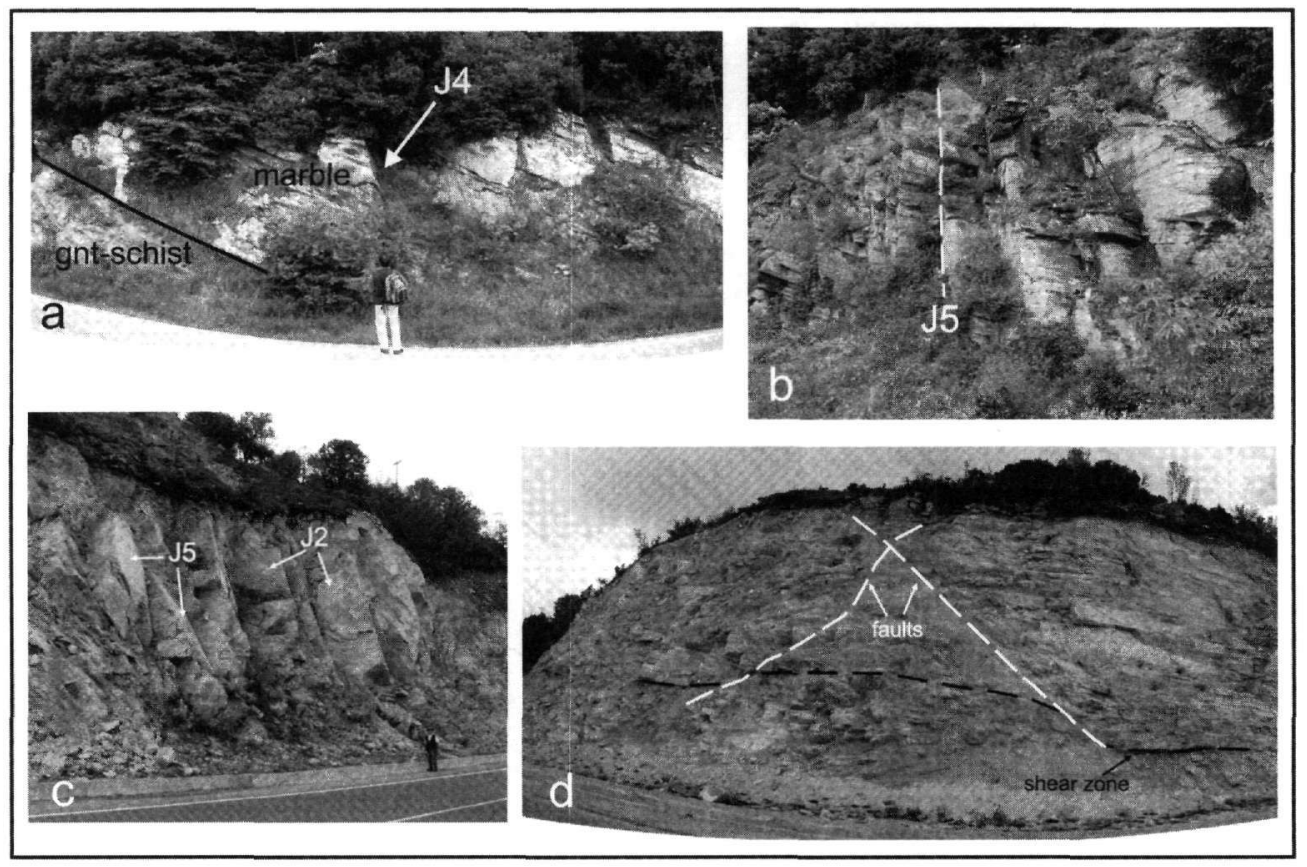

Figure 6 - (a) The tectonic contact of the Lower Carbonate horizon with the underlying garnet-mica schist and joints of the J4-joint set, (b) joints of the J5-joint set that form a fracture zone within the mica schist (map A), (c) joints of the $\mathrm{J} 2$ and $\mathrm{J5}$ joint sets in the orthogneiss (section B5 map B), (d) normal faults in the orthogneiss cutting a semi-brittle shear zone sub-parallel to the foliation

The original analysis showed that the potential failures were mainly relating to rock wedge formation, whereas no conditions favoring planar, circular or toppling failure were found (Hoek and Bray 1981). The rock wedges representing potential instability factors were next analysed using the friction cone method, and the factor of safety $\left(F=\tan \varphi_{i} / \tan n_{i}\right)$ for each one was calculated to determine the probability of failure. Figure 7 shows two examples of these analyses. The first one refers to segment A3 within which the road cuts through the mica schists and the created slopes' average orientation is $125^{\circ} / 70^{\circ}$ (map A). The angles were approximately estimated from tables by Hoek and Bray (1981) for schistose rocks as $\varphi_{1}=23^{\circ}$ and $\varphi_{2}=23^{\circ}$ (lowest values). The analysis produced angles $\varphi_{\mathrm{i}}=61^{\circ}$ and $\mathrm{n}_{\mathrm{i}}=41^{\circ}$, which give a factor of safety for this rock wedge of $\mathrm{F}=2,08$. Therefore the rock wedges that might occur in the A3 segment of the road, by the intersections of the two respective joint sets, are not expected to cause stability problems in the slope. The slope angle could be safely increased. The next example refers to segment A5 where the road cuts through the garnet-mica schists and the created slopes' average orientation is $170^{\circ} / 70^{\circ}$ (Fig. 4). The friction angles used approximately from referenced tables regarding schistose rocks, were $\varphi_{1}=23^{\circ}$ and $\varphi_{2}=23^{\circ}$ (Hoek and Bray 1981). The analysis produced angles $\varphi_{\mathrm{i}}=42^{\circ}$ and $\mathrm{n}_{\mathrm{i}}=52^{\circ}$. The factor of safety for the specific type of rock wedges was calculated $\mathrm{F}=0,7$. Therefore the rock wedges that might occur in the A5 segment of the road, by the intersections of the two respective joint sets, pose a failure hazard, which might cause stability problems in the slope. The failure problems detected in these locations indicate the implementation of control measures which must be reviewed and evaluated, such as modifying the orientation of the road prior to its construction, reduction of slope heights to angles determined by Markland's test or finally installation of slope support measures (bolts, anchors, retaining structures etc.). 


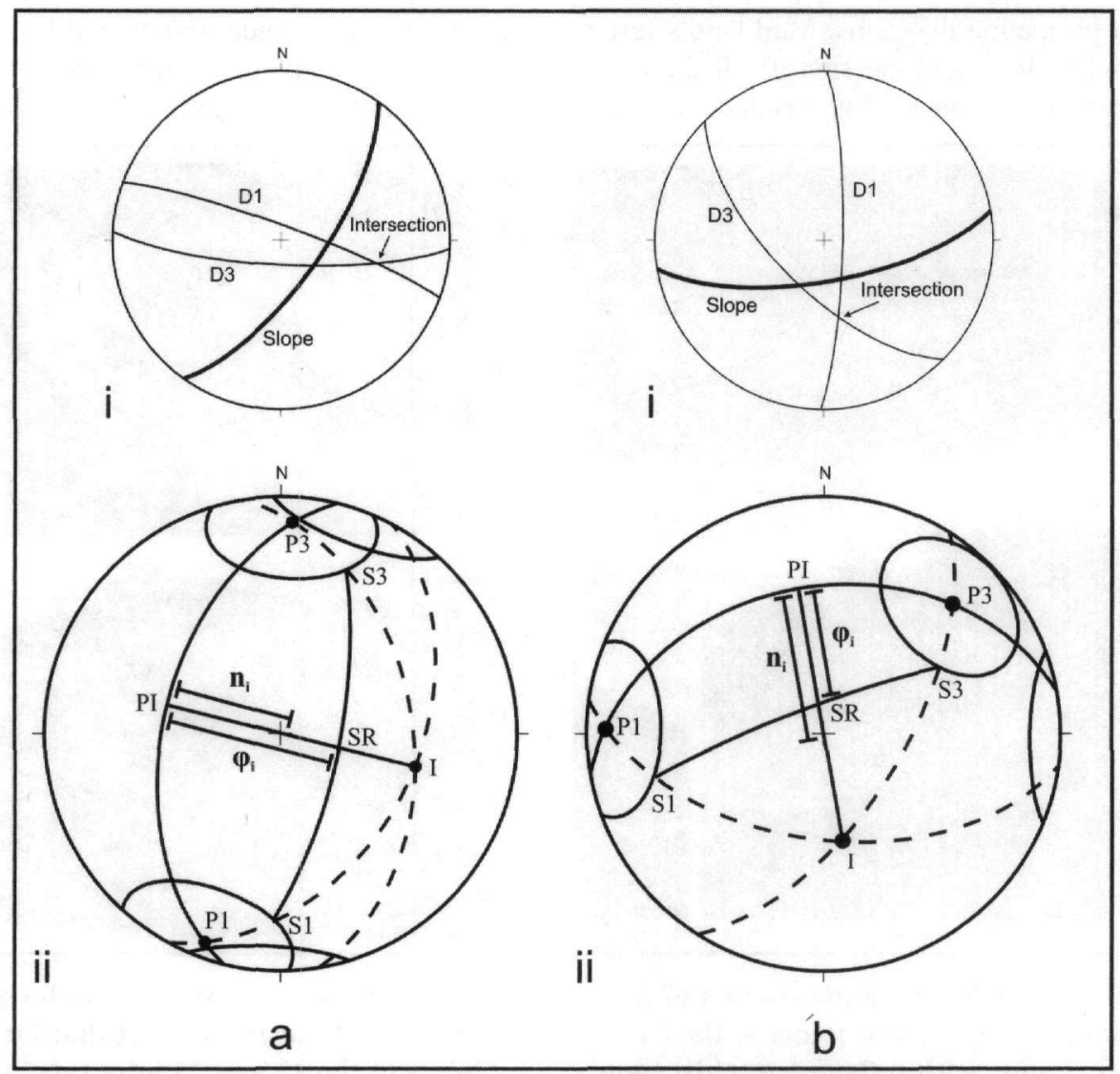

Figure 7 - Rock wedge analysis in sections A3 (a) and A5 (b) of the road. The diagrams present the slope orientation and the discontinuities forming the wedge

\section{Conclusions}

The geological mapping carried out in the framework of major works construction ought to take into account every requirement of basic geological mapping and, additionally, data regarding the physical and mechanical properties of the geological formations. The additional data should be determined by direct field observations (e.g. description of discontinuities) as well as sampling and laboratory testing (e.g. shear strength of discontinuities).

The optimal combination of all these elements leads to significant reduction of the construction cost with a corresponding increase of the construction safety. This would not be the case if the design of the construction was based exclusively on the results of basic geological mapping.

\section{References}

Anon, 1977. The description of rock masses for engineering purposes, Working party report, Q. J. Engg Geol., 10, 355-388.

Barton, N., 1978. Suggested methods for the quantitative description of discontinuities in rock masses. ISRM commission on standardization of laboratory and field tests, Int. J. Rock Mech. Min. Sci. \& Geomech. Abstr., 15, 319-368.

Chistaras, B., Zouros, N., Makedon, Th., and Dimitriou, A., 1997. Adverse geotechnical conditions in road construction: Section of the new Egnatia highway across Pindos 
mountain range, N. Greece. In P. G. Marinos, G. C. Koukis, G. C. Tsiambaos and G. C. Stournaras (eds), Engineering Geology and the Environment, 3, 2639-2645pp.

Hoek, E., and Bray, W. J., 1981. Rock slope engineering, 3rd edition. Institution of mining and metallurgy, 358pp.

ISRM (International Society for Rock Mechanics), 1981. Rock characterization testing and monitoring: In E.T. Brown, (ed.), ISRM Suggested Methods, Pergamon Press.

Kilias, A., and Mountrakis, D., 1989. The tectonic cover of Pelagonia. Tectonics, metamorphism and magmatism. Bull. Gel. Soc. Greece XXIII/1, 29-46. (in Greek)

Koroneos, A., Tsoutsika, P., Eleftheriades, G., and Seidel, E., 2000. Mineralogy, petrology and geochemistry of the plutonite of Kastania (Vermio), Proceedings of the $1^{\text {st }}$ conference of the committee of economic geology, mineralogy and geochemistry of the Hellenic Geological Society, 223-242. (in Greek)

Mercier, J.-L., Simeakis, K., Sorel, D., and Vergely, P., 1989. Extensional tectonic regimes in the Aegean basins during the Cenozoic, Basin Research, 2, 49-71.

Mountrakis, D., 1983. Structural geology of the North Pelagonian zone s.l. and geotectonic evolution of the internal Hellenides, 'Habilitation' thesis, University of Thessaloniki. (in Greek with English summary)

Mountrakis, D., Tranos, M., Papazachos, C., Thomaidou, E., Karagianni, E., and Vamvakaris, D., 2006. Neotectonic and seismological data concerning major active faults, and the stress regimes of Northern Greece. In A. H. F. Robertson and D. Mountrakis (eds), Tectonic Development of the Eastern Mediterranean Region. Geol. Soc. London, Spec. Publications 260, 649-670pp.

Ouzounis, A., Kilias, A., and Mountrakis, D., 2002. The use of Digital Elevation Models (D.E.M.) and Geographic Information System (G.I.S.) in geological mapping. A case study in the southern Vermion Mountain (SW Macedonia, Greece), Proceedings of the $6^{\text {th }}$ Pan-Hellenic Geographical Conference of the Hellenic Geographical Society vol. II, 193-200.

Park, H.-J., West, T. R., and Woo, I., 2005. Probabilistic analysis of rock slope stability and random properties of discontinuity parameters, Interstate Highway 40, Western North Carolina, Usa, Engineering Geology 79, 230-250.

Photiades, A., 2004. Geological mapping revision of the Vermion Mountain (Internal Hellenides, Greece). In A. A. Chatzipetros and S. B. Pavlides (eds), Proceedings of the $5^{\text {th }}$ International Symposium on the Eastern Mediterranean geology vol. 1, 161-164pp.

Yarwood, A. G., and Aftalion, M., 1976. Field relations and U-Pb geochronology of a granite from the Pelagonian zone of the Hellenides (High Pieria, Greece), Bull. Soc. Geol. France (7), t. XVIII N ${ }^{0} 2,259-264$. 